\title{
PHOTOCHEMISTRY OF DIAZOCOMPOUNDS AND AZIDES IN ARGON
}

\section{L. Chapman}

Department of Chemistry, University of California, Los Angeles, 405 Hilgard Avenue, Los Angeles, California 90024, USA

Abstract. The synthetic applications and mechanistic complications of a variety of photochemical rearrangements of diazocompounds and azides matrix isolated in argon are described.

The introduction of matrix techniques to the synthesis and study of reactive organic molecules has substantially extended the range of molecules available for investigation (Ref. 1). It is now increasingly the case that we need new chemical methods to make progress in this area of investigation. Diazocompounds and azides have proved especially useful as starting points for a new style of photochemical synthesis operating within the severe limits imposed by the rare gas matrix environment. We have now made significant progress in developing rationally designed syntheses in the matrix environment and in so doing we have encountered a number of amusing and sometimes important mechanistic observations that have implications for the room temperature environment. It is the purpose of this communication to present some of our syntheses and the related mechanism studies.

The photochemical Wolff rearrangement has proved to be among the most generally useful and reliable synthetic reactions in the matrix environment. It is thus fitting that we begin our discussion with this reaction. In using the photochemical Wolff rearrangement one must deal with the question whether or not this process in a matrix at low temperature $(8-12 K)$ is a concerted process or involves a carbene. This issue can be probed by intramolecular and intermolecular trapping experiments. We shall consider the intramolecular trapping test first. A suitably disposed double bond provides a possible trap for an intermediate acyl carbene. Irradiation of vinyl diazomethyl ketone (1) in an argon matrix gave vinyl ketene<smiles>C=CC(=O)C=O</smiles>

1
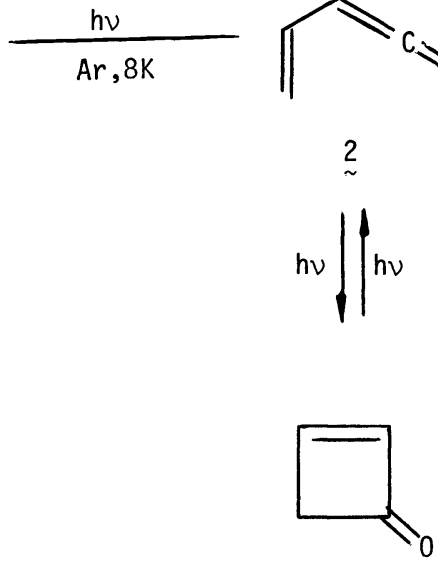

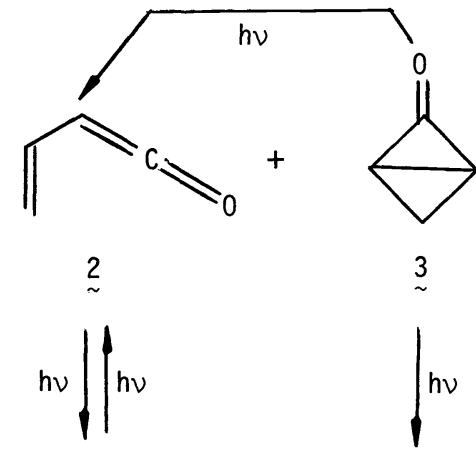

2

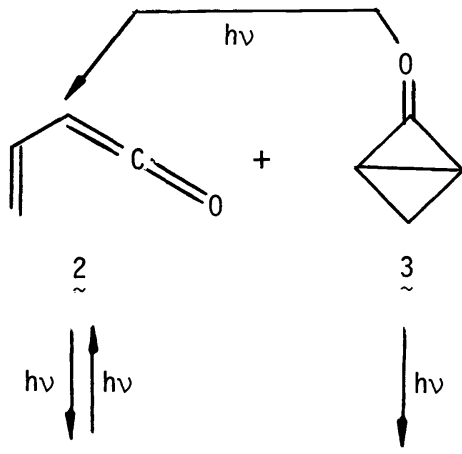

$\mathrm{CO}+$<smiles>C1=CC1</smiles>

(2) and bicyclobutanone $\left(\underline{3}, 1840 \mathrm{~cm}^{-1}\right.$ ) (Ref. 2). Vinylketene was identified by its infrared absorption and photochemical interconversion with authentic cyclobutenone. Bicyclobutanone photochemically decomposes to vinylketene 
(major) and decarbonylates to cyclopropene (minor). Irradiation of allenyl diazomethyl ketone (4) gives allenylketene (ㅁ) and methylenebicyclobutanone (6) (Ref. 2). Formation of the

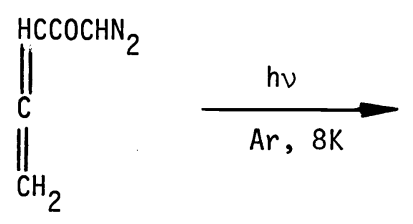

$\underline{4}$<smiles>C=C=CC=C=O</smiles>

$\underline{5}$<smiles>C=C1CC2CC12</smiles>

$\underline{6}$

bicyclobutanones ( 3 and $\underline{6}$ ) is sensible only in terms of an intermediate carbene, and at least part of the reaction mus follow this course. Concerted addition of the carbene to the olefin

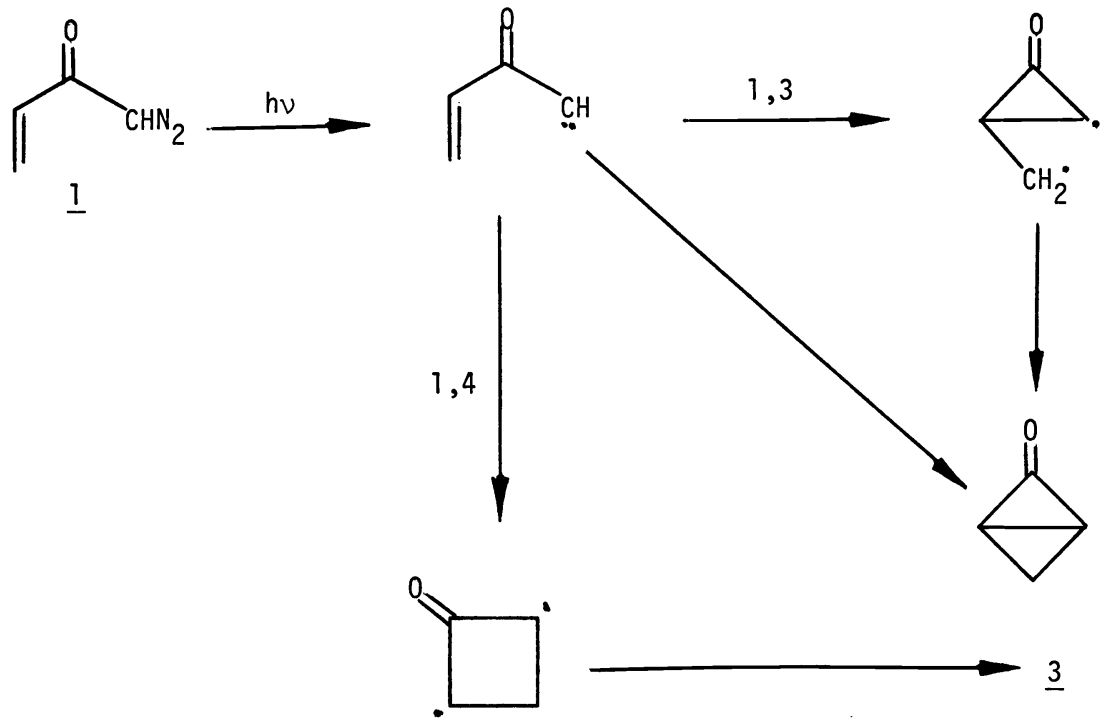

or initial 1,3 or 1,4-bonding leading via a diradical intermediate to the bicyclobutanone can be imagined. The multiplicity of the intermediates is unfortunately not known. The question whether carbene formation is the major route leading to ketene formation in an argon matrix or whether it is a minor process is not answered by the experiments with the unsaturated diazomethyl ketones ( 1 and $\underline{4})$. Intermolecular trapping provides further insights.

Irradiation of diazoacenaphthenone (7) in argon gives cleanly the ring contracted ketene (8) (Ref. 3). This observation is in sharp contrast to experience with 7 in solution at room temperature in which several products (none involving ring contraction) are observed. The<smiles>O=C1C(=[W])c2cccc3cccc1c23</smiles>

$\underline{7}$<smiles>O=C1c2cccc3cccc1c23</smiles>

8

formation of the very strained ketene 8 shows one example of the use of the photochemical Wolff rearrangement in the matrix synthesis of reactive molecules. If the irradiation of 7 is carried out in a matrix of argon ( $80 \%)$ and oxygen $(20 \%)$, the ketene is not formed and the new product is the anhydride (9) of naphthoic acid (Ref. 3). No nitrous oxide $\left(\mathrm{N}_{2} \mathrm{O}\right)$ is 
<smiles>N#CC1C(=O)c2cccc3cccc1c23</smiles>

?

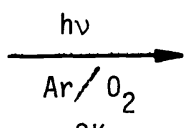

$8 \mathrm{~K}$<smiles>O=C1OC(=O)c2cccc3cccc1c23</smiles>

$\underline{9}$

formed in this process. The reaction is simply understood in terms of oxygen trapping of an acyl carbene (10) which gives ketene or is trapped by oxygen giving either the dioxirane (11)<smiles>N#CC1C(=O)c2cccc3cccc1c23</smiles>

I

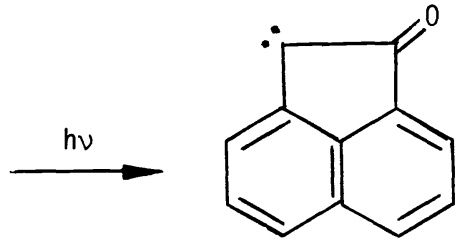

10<smiles>Cc1ccc2cccc3c2c1C3=O</smiles>

$\underline{8}$

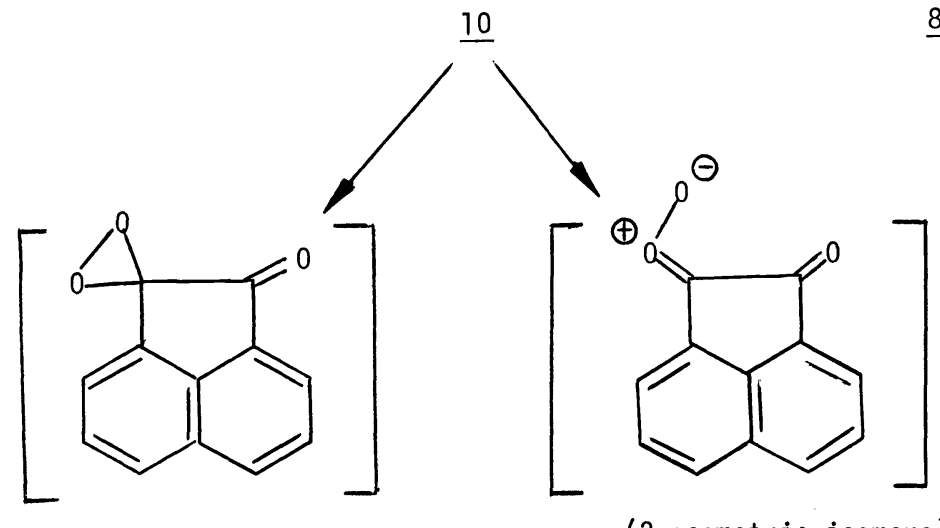

(2 geometric isomers)

11
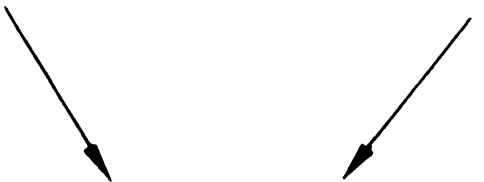<smiles>O=C1OC(=O)c2cccc3cccc1c23</smiles>

$\underline{9}$

or the carbonyl oxide (12). Either oxygen trapped product is a sensible precursor for the anhydride (9). This trapping experiment raises several questions: (1) What is the multiplicity of the acyl carbene (10)? (2) Does the presence of oxygen in the matrix perturb the normal reaction by enhancing intersystem crossing? (3) Does the addition of oxygen to a carbene give a dioxirane, a carbonyl oxide, or both? We have not been successful in obtaining answers to the first two questions, but we have been able to obtain an answer for the third question in one system. Irradiation of diazocyclopentadiene (13) in an argon matrix gives triplet cyclopentadienylidene (14) (Ref. 4). If the irradiation is carried out in an 
<smiles>[Y]=C1C=CC=C1</smiles>

13

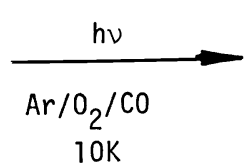

10K<smiles>[C]1C=CC=C1</smiles>

14

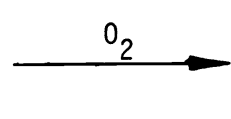<smiles>[O-][O+]=C1C=CC=C1</smiles>

5<smiles>O=C=C1C=CC=C1</smiles>

16

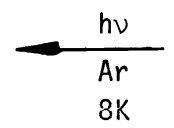

8K<smiles>[Y]=C1C=CC=CC1=O</smiles>

17

argon/oxygen matrix, the product is cyclopentadiene-0-oxide (15) (Ref. 5). This is the first spectroscopic observation of a carbonyl oxide. Trapping evidence for the existence of these species in solution has been presented earlier by Bartlett (Ref. 6) and by Murray (Ref. 7). Experiments using argon/oxygen/carbon monoxide matrices show that oxygen and carbon monoxide compete for a common intermediate (Ref. 5). The ketene (16) has been independently synthesized by irradiation of diazoketone 17 (Ref. 8). The photochemistry of the carbonyl oxide is of some interest. Two major paths of reaction are noted. The first path involves oxygen atom donation (possibly via a cyclic adduct) to oxygen giving cyclopentadienone (18) and ozone (Ref. 5). The second pathway gives cyclopentadienone epoxide (19), the aldehyde-

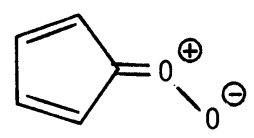

15

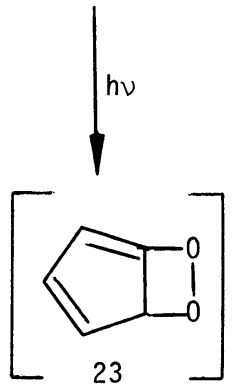

hv

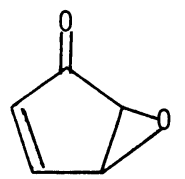

19
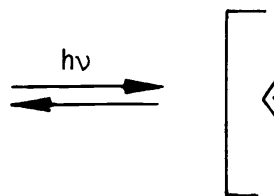<smiles>CCOC1=CC=CC1O</smiles><smiles>[Mg][Mg]Br</smiles>

10K<smiles>O=c1cccco1</smiles>

21<smiles>C[C@@H](C=O)/C=C\C=O</smiles> 
ene-ketene (20), and 2-pyrone (21) (Ref. 5). All of these products come yia diradical 22 which can be generated independently by irradiation of cyclopentadienone epoxide (19) (Ref. $5)$. The dioxetane (23) appears to be the most likely precursor for 22.

We now turn to a few examples of the use of the photochemical Wolff rearrangement in the synthesis of reactive molecules. The prototype example of designed matrix synthesis using the Wolff rearrangement is our scheme for the introduction of strained multiple bonds using diazobutyrolactone precursors. The synthesis of benzyne (22) from diazolactone (23) provides an example (Ref. 9). Elimination of a small stable molecule (nitrogen or carbon monoxide)<smiles>N=C1C(=O)Oc2ccccc21</smiles>

$\underline{23}$

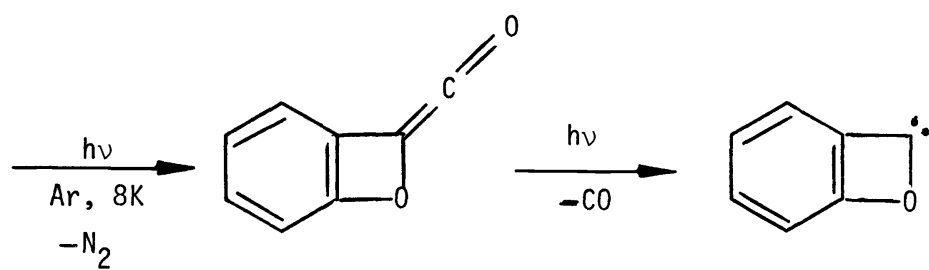

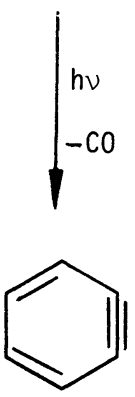

provides a driving force for each stage of the synthesis as the degree of strain is increased. A different example of the use of this strategy is provided by the synthesis of the strained ketone $24\left(\nu_{\mathrm{CO}} 1810 \mathrm{~cm}^{-1}\right)$ (Ref. 10) from the diazolactone 25 . Ketone 24 is remarkably<smiles></smiles>

25<smiles>O=C=c1c(=O)c2cccc3cccc1c32</smiles><smiles>O=C1c2cccc3cccc1c23</smiles>

24

strained. This can be best appreciated by considering its relationship to 1,2-cyclobutadien3-one (26). Bis-diazoketones have also proved useful in matrix synthesis. Following Trost's<smiles>O=C1C=C=C1</smiles>

$\underline{26}$

lead (Ref. 11), we examined the photochemistry of 2,6-bis-diazocyclohexanone (27) in argon (Ref. 12). We were able to observe the diazoketene (28) and the cyclopropenone (29) 
<smiles>N=C1CCCC(=O)C1=O</smiles>

$\underline{27}$<smiles>O=C=C1CCCC1=[W]</smiles>

$\underline{28}$

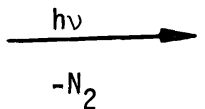<smiles>C=C=C1CC1</smiles>

hv

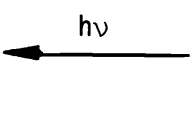

31<smiles>O=C1C2=C3CCCC132</smiles>

29

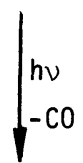<smiles>C1#CCCC1</smiles>

30

postulated by Trost. Decarbonylation of 29 gave a highly photolabile species 30 which we believe to be cyclopentyne. The ultimate product is the allene 31 which is indefinitely stable to UV in a matrix. Attempts to make the next lower homolog of 30 , cyclobutyne (32) have the additional complication that this highly strained system can open to butatriene (33).

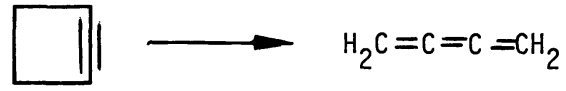<smiles>C1#Cc2ccccc21</smiles>

$\underline{34}$

This difficulty can be overcome by using cyclic derivatives such as benzocyclobutyne (34). Irradiation of 1,3-bis-diazo-2-indanone (35) gives first a diazoketene (36) then a rather remarkable cyclopropenone (37) (Ref. 13). Cyclopropenone 37 is the only cyclopropenone we<smiles>N=c1c(=O)c(=N)c2ccccc12</smiles>
$\underline{35}$

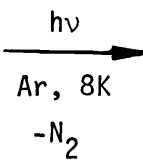

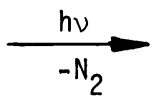

$\mathrm{N}_{2}$<smiles>O=c1c2c1-c1ccccc1-2</smiles>

37

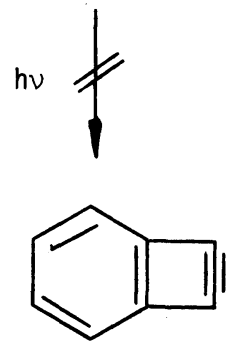

34

have encountered which we could not photodecarbonylate. A further variation on the theme of the Wolff rearrangement is a sequence designed to generate cyclopenta-1,2-diene. Irradiation of the diazodione 38 gives a keto-ketene (39), then a strained bicyclic ketene (40) (Ref. 14). Photodecarbonylation of this ketene gives cyclopropylacetylene (41) and 1-vinylcyciopropene (42) (Ref. 14). These products are sensibly derived by [1,3s] sigmatropic rearrangements from 


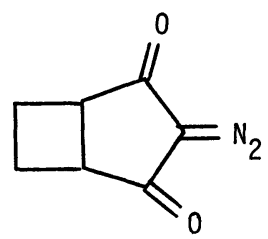

38 (n)

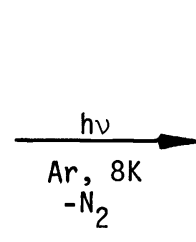

1

$\underline{9}$
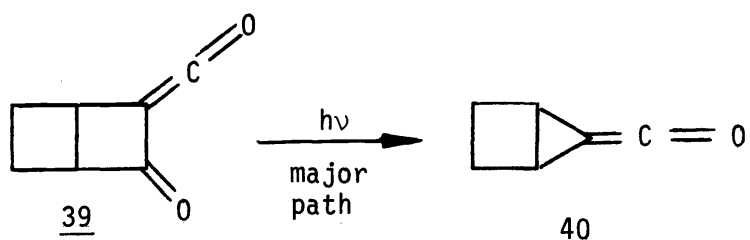

$\underline{40}$

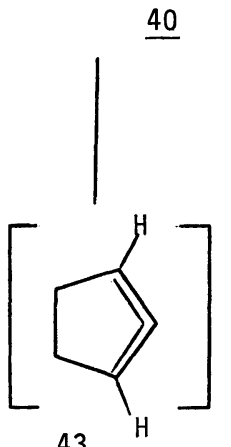

$\square+\mathrm{C}_{3} \mathrm{O}_{2}$

41 ho

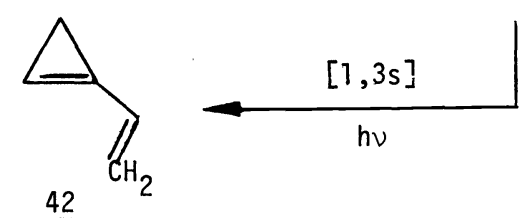

1,2-cyclopentadiene (43). Unfortunately, the rate of destruction of 43 exceeds the rate of formation from 40 . The decarbonylation of the ketene $(\underline{40})$ is rather slow.

The difficulties encountered in our attempts to synthesize 1,2-cyclopentadiene caused us to retreat and consider approaches to cummulene synthesis in six, seven, and eight-membered rings. Our first success came with the photochemical ring expansion of phenyl azide (44) and 2-pyridylmethylene (ㄷ) to 1-aza-1,2,4,6-cycloheptatetraene (46) (Ref, 15). A variety<smiles>[N]c1ccccc1</smiles>

44<smiles>[N]c1ccccn1</smiles>

$\underline{47}$<smiles>Br[Mg]Br</smiles>

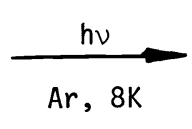

46<smiles>C1=CC=CN=C=NC=1</smiles>

$\underline{48}$

of such ring expansions have now been realized. Irradiation of 2-azidopyridine (47 generated from tetrazolopyridine), for example, gives the cyclic carbodimide (48, $\nu_{\text {cc }} 1995 \mathrm{~cm}-1$ ) (Ref. 16). Similar irradiation of 3-diazomethylpyridine (49) and 4-diazomlethylpyridine (50) gave a common product, the allene 51 (Ref. 17). It is possible using ESR studies to monitor<smiles>N#Cc1cccnc1</smiles>

$\underline{49}$

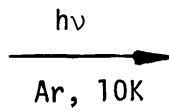

Ar, $10 \mathrm{~K}$

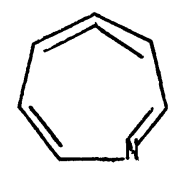

51

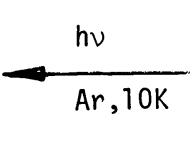<smiles>O=Cc1ccncc1</smiles>

50 
the triplet products from phenyl azide and the three isomeric pyridylmethylenes. Irradiation $(\lambda>2000 \AA)$ of either phenyl azide or 2-diazomethylpyridine gives both triplet phenylnitrene (52) and triplet 2-pyridylmethylene (53) (Ref. 17). Similar irradiation of 3-diazomethyl-

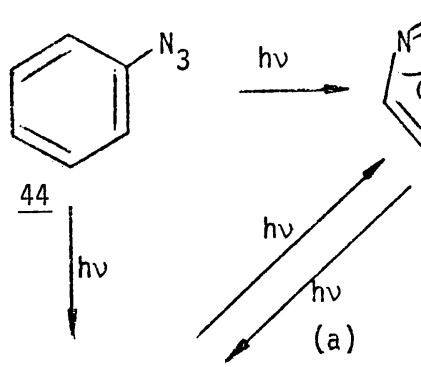

(a)<smiles>CCc1ccccc1</smiles><smiles>N#Cc1ccccn1</smiles><smiles>c1ccn2nncc2c1</smiles>

(b)<smiles>CCCCCCCCCCCCCC</smiles>

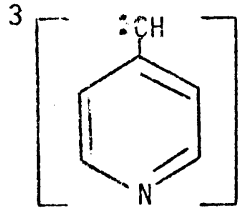<smiles>CC(C)CCCCCc1ccncc1</smiles><smiles>CCC</smiles><smiles></smiles>

51

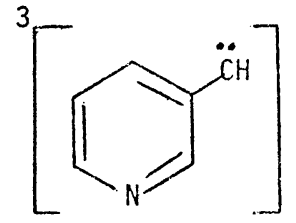

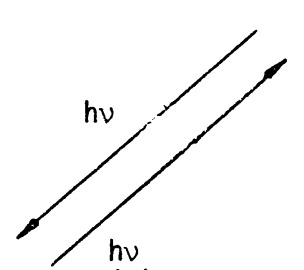

(b)

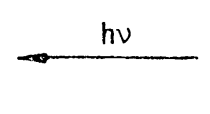<smiles>N#Cc1cccnc1</smiles>

49

pyridine (49) or 4-diazomethylpyridine (50) gives triplet phenylnitrene (52), triplet 2pyridylmethylene (53), triplet 3-pyridylmethylene (54, two rotomers), and triplet 4-pyridylmethylene (55) (Ref. 17). The triplets are sensibly interconverted by photochemical 1,2shifts in the observed cummulenes ( $\underline{46}$, and $\underline{51}$ ) and the postulated allene ( $\underline{56})$.

This brief discussion can only serve as an introduction to synthetic utility of diazocompounds and azides in the matrix environment and to the mechanistic complexities one encounters as more detailed observations become possible. 
Acknowledgment. I wish to express my deep appreciation to and my great respect for my coworkers in the low temperature research described above. Individual citations have been made throughout the manuscript. Financial support for these investigations was provided by grant (MPS75-10939) from the National Science Foundation and by grant (GM-24427) from the National Institute of General Medical Sciences, U.S. Department of Health, Education and Wel fare.

\section{References}

1. 0.L. Chapman, Pure and Appl. Chem., 40, 51 (1974) and references cited therein.

2. Unpublished observations of O.L. Chapman, C.-C. Chang, and N. Rosenquist.

3. Unpublished observations of O.L. Chapman and T.C. Hess.

4. E. Wasserman, L. Barash, A.M. Trozzolo, R.W. Murray, and W.A. Yeager, J. Am. Chem. Soc., 96, 2304 (1964); M.S. Baird, I.R. Dunkin, and M. Poliakoff, J. Chem. SoC. D., 904 (1974).

5. O.L. Chapman and T.C. Hess, J. Am. Chem. Soc., submitted for publication.

6. P.D. Bartlett and T.G. Traylor, J. Am. Chem. Soc., 84, 3408 (1962).

7. R.W. Murray and D.P. Higley, J. Am. Chem. Soc., 95, 7886 (1973).

8. Unpublished observations of $0 . L$. Chapman and C. Sukenik.

9. O.L. Chapman, C.-C. Chang, J. Kolc, N.R. Rosenquist, and H. Tomioka, J. Am. Chem. Soc., 97, $6586(1975)$.

10. Unpublished observations of $0 . L$. Chapman and R.A. Hayes in collaboration with $J$. Meinwald, M. Louden, and C. Semmelhack.

11. B.M. Trost and P.J. Williams, J. Am. Chem. Soc., 96, 7421 (1974).

12. Unpublished observations of O.L. Chapman and J. Gano.

13. Unpublished observations of O.L. Chapman and D.C. Roberts.

14. Unpublished observations of O.L. Chapman and C. Sukenik in collaboration with M. Oda.

15. O.L. Chapman and J.-P. LeRoux, J. Am. Chem. Soc., 100, 282 (1978).

16. Unpublished observations of O.L. Chapman and J.-P. LeRoux.

17. O.L. Chapman and R.S. Sheridan, J. Am. Chem. Soc., in press. 